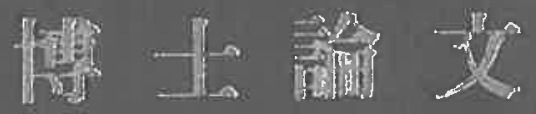

Polyacrylic scid-metall adhesive bond joint

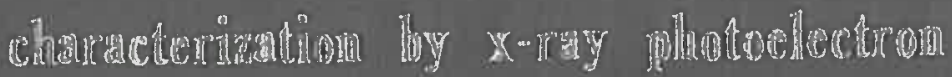

spectirascopy

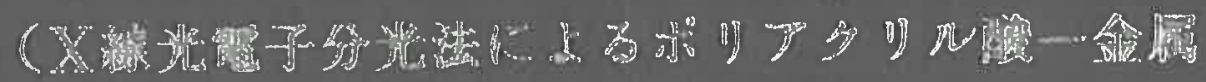

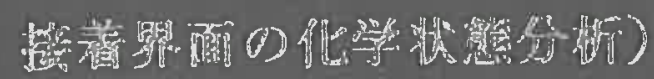

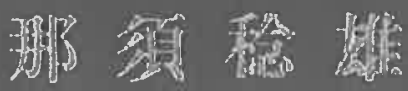

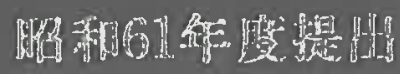

垶非头等 


\section{Polyacrylic acid-metal adhesive bond joint characterization by $x$-ray photoelectron spectroscopy}

Toshio Nasu
Faculty of Education, Yamagata University, Yamagata, Japan

Reprinted from

Journal of Biomedical Materials Research, March 1986

(c) 1986 by John Wiley \& Sons, Inc. 


\title{
Polyacrylic acid-metal adhesive bond joint characterization by $x$-ray photoelectron spectroscopy
}

\author{
Toshio Nasu \\ Faculty of Education, Yamagata University, Yamagata, Japan
}

The adhesive force to human tooth and metallic restoration of dental cements which contain polyacrylic acid (PAA) is found to be stronger than that of previous cements. Chemical interaction at the interface between metals and carboxylate groups of PAA were studied by $x$-ray photoelectron spectroscopic method combined with $\mathrm{Ar}^{+}$-ion beam etching technique to examine the mechanism of adhesion. A $2.5 \mathrm{wt} \%$ aqueous solution of PAA was painted on the surface of metal plates which are usual elements of dental alloy. $\mathrm{Ar}^{+}$-ion etching was used to scrape off in situ the PAA film coated on the metal plate gradually in the sample chamber of the ESCA equipment. After a few minutes of etching, ESCA spectra were observed. The profile of the spectra and binding energy of $4 f_{5 / 2}$ and $4 f_{7 / 2}$ levels of Au coated with PAA show little change by the $\mathrm{Ar}^{+}$-ion etching, and remain in the same state as those of uncoated $\mathrm{Au}$. Similar behaviors were obtained in case of Pt. There are three chemical states on Sn plate coated with PAA. The lowest binding energy peak is assigned to pure Sn. The middle one is assigned to $\mathrm{SnO}_{2}$. The highest one corresponds to $\mathrm{Sn}$ combined with carboxylate groups of PAA. The chemical reaction corresponding to the highest binding energy peak seems to contribute to the strong adhesive force of these cements to Sn. These aspects of spectra corresponded to McLean's results which showed that these cements had weak adhesion to $\mathrm{Au}$ and $\mathrm{Pt}$, but strong adhesive force to tinned $\mathrm{Au}$ and Pt.

\section{INTRODUCTION}

The whole phenomenon of the adhesion of dental cements is complex. The cement, in the setting process after mixing, contacts the metal restoration and the tooth substance. Many things are occurring at the same time, ${ }^{1-3}$ so that adhesive force is composed of many factors. The electrostatic contribution and chemical contribution are of course only a portion of the total forces acting. But these contributions are very important from the standpoint of margin closure and endurance of bond joint. Carboxylate groups of polyacrylic acid seem to react with the metal restoration and calcium in tooth enamel, as a basis of strong adhesive force of the cements containing PAA. D. C. Smith described the adhesion mechanism of dental cements which contain PAA. ${ }^{4,5}$ PAA has been assumed to chelate with calcium in enamel. D. R. Beech showed that PAA reacts with calcium ions in enamel powder in his infrared spectroscopic study. ${ }^{6}$ There have been several investigations about the chemical reaction between polyacrylic acid and metal ${ }^{7-11}$ or metal Journal of Biomedical Materials Research, Vol. 20, 347-362 (1986) (C) 1986 John Wiley \& Sons, Inc.

CCC 0021-9304/86/030347-16\$04.00 
oxide. ${ }^{12}$ But few experiments have been performed concerning the chemical interaction at the intact bond joint of metal and polyacrylic acid. A technique is presented in which the chemical state of intact bond joints can be studied using x-ray photoelectron spectroscopy (ESCA), ESCA technique offers information of the chemical state on a solid surface to a 10-40 $\AA$ depth. ${ }^{13}$ Different chemical states of an atom give chemical shifts in ESCA spectra. ${ }^{14}$ Therefore, ESCA technique is a suitable technique to perform the chemical state analysis of PAA-metal adhesive bond joints. ${ }^{15} \mathrm{Ar}^{+}$-ion beam etching was applied to the metal plate coated with PAA to scrape the PAA gradually in the sample chamber of ESCA equipment. After a few minutes of etching, ESCA spectra were measured. Thus the chemical state of the metal near the interface between the PAA and metal was analyzed to examine the chemical constituent of the strong adhesive force of the cement.

\section{MATERIALS AND METHODS}

\section{Specimen preparation}

Gold, platinum, silver, copper, cobalt, chromium, tin, and indium which are elements of dental alloys were selected for study. These were supplied by Hirano Metal and Alloy Corporation, Tokyo, Japan. The metal purity was upward of $99.9 \mathrm{wt} \%$. Metals were prepared in a plate shape, $5 \times 12 \times$ $0.5 \mathrm{~mm}$. These metal plates were polished with No. 600 emery paper, and then painted with a $2.5 \%$ by weight aqueous solution of PAA, and dried in a desiccator for $24 \mathrm{~h}$. The standard metal compounds used to assign the peaks in the ESCA spectra were supplied by Wako Pure Chemical Industries, Osaka, Japan.

\section{Argon ion etching}

$\mathrm{Ar}^{+}$-ion etching was used to gradually scrape off the PAA film coated on the metal surface in the sample chamber of an ESCA spectrometer. A schematic illustration of argon ion etching is shown in Figure 1. High purity argon gas was led in to the ionization chamber at about $5 \times 10^{-5} \mathrm{~mm} \mathrm{Hg}$. The argon ion beam was generated with a PHI Model 04-161 Sputter Ion Gun

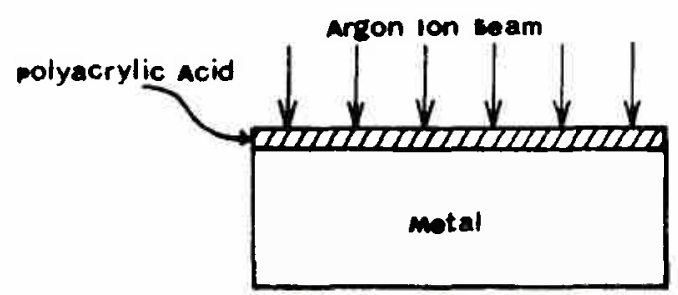

Figure 1. Schematic figure of argon ion etching of metal surface coated with PAA. 
which was operated with a beam potential of $1.5 \mathrm{kV}$ and electron emission current of $20 \mathrm{~mA}$.

\section{ESCA measurement}

Experiments were performed in the AEI ES 200 electron spectrometer using $\mathrm{Mg} K_{\alpha}$ radiation $(1253.6 \mathrm{eV})$. The $\mathrm{Au}\left(4 \mathrm{f}_{5 / 2}, 4 \mathrm{f}_{7 / 2}\right)$ binding energy, $87.74 \mathrm{eV}$, $84.07 \mathrm{eV}$, was used for calibration of the equipment. Oil diffusion pumps fitted with cold traps produce a vacuum of $5 \times 10^{-8} \mathrm{~mm} \mathrm{Hg}$. After a few minutes of argon ion beam etching, the ESCA spectra were measured. Wide range ESCA spectra (binding energy: 0 to $1000 \mathrm{eV}$ ) was measured first, and a level of the largest intensity peak was chosen for chemical state analysis. The measurement was performed within the $10 \mathrm{eV}$ range with centers of peaks at $0.1 \mathrm{eV}$ steps. The argon ion beam etching and ESCA measurement were repeated alternately. When the PAA was removed from the metal surface by the etching, the ESCA measurement was concluded. Experimental spectra which were deconvoluted into separate components assumed Gaussian distribution. Thus the chemical states of the metals near the interface between PAA and metal were analyzed.

\section{RESULTS AND DISCUSSION}

\section{Gold and platinum}

Experimental ESCA spectra of Au coated with PAA are illustrated as a function of $\mathrm{Ar}^{+}$-ion etching duration in Figure 2. The abscissa shows binding energy of the photoelectron released from the sample. The ordinate shows the intensity of the photoelectron in an arbitrary unit. The profile of the spectra and binding energy of $4 \mathrm{f}_{5 / 2}$ and $4 \mathrm{f}_{7 / 2}$ levels of Au coated with PAA do show little change by $\mathrm{Ar}^{+}$-ion etching and remain in the same state as those of uncoated $\mathrm{Au}$. Binding energy of electron in $4 \mathrm{f}_{5 / 2}$ and $4 \mathrm{f}_{7 / 2}$ orbitals are $87.74 \mathrm{eV}$ and $84.07 \mathrm{eV}$, respectively. The ESCA spectra of Pt coated with PAA are illustrated in Figure 3. Similar results to Au were obtained in the case of $\mathrm{Pt}$. Binding energy of electrons in $4 \mathrm{f}_{5 / 2}$ and $4 \mathrm{f}_{7 / 2}$ orbitals are $74.60 \mathrm{eV}$ and $71.29 \mathrm{eV}$, respectively. These results show that the chemical reaction with chemical shift in ESCA spectra does not occur at the interface when $\mathrm{Au}$ and $\mathrm{Pt}$ are coated with PAA, and correspond with a previous observation that the cements have weak adhesive strength to $\mathrm{Au}$ and $\mathrm{Pt}^{16}$

\section{Silver and copper}

Experimental ESCA spectra of $\mathrm{Ag}$ coated with PAA are illustrated as a function of $\mathrm{Ar}^{+}$-ion etching duration in Figure 4. The profile of $\mathrm{Ag} 3 \mathrm{~d}_{5 / 2}$ level on the unetched sample shows a peak at $368.05 \mathrm{eV}$ and a shoulder at 


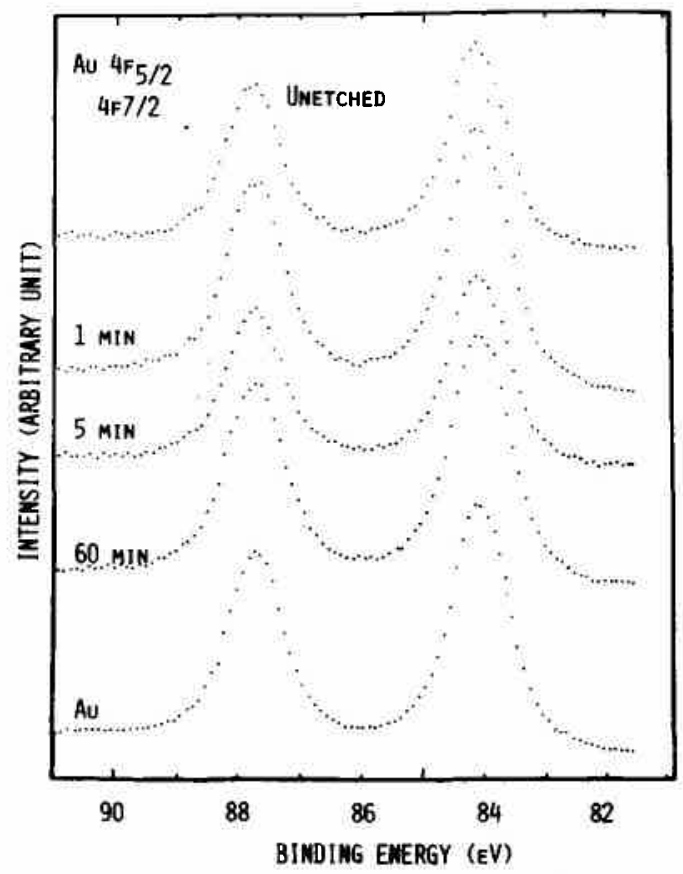

Figure 2. X-Ray photoelectron spectra of $A u 4 f_{5 / 2}, 4 f_{7 / 2}$ levels of Au coated with PAA and etched by argon ion beam for 1,5 , and $60 \mathrm{~min}$ and pure $\mathrm{Au}$ metal.

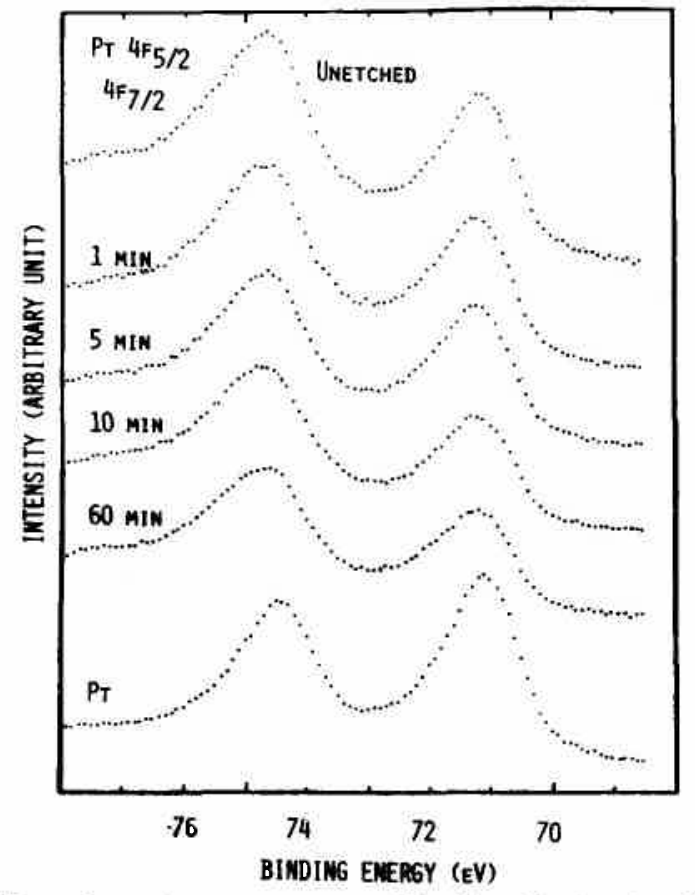

Figure 3. X-Ray photoelectron spectra of $\mathrm{Pt} 4 \mathrm{f}_{5 / 2}, 4 \mathrm{f}_{7 / 2}$ levels of $\mathrm{Pt}$ coated with PAA and etched by argon ion beam for 1, 5, 10, and $60 \mathrm{~min}$ and pure Pt metal. 


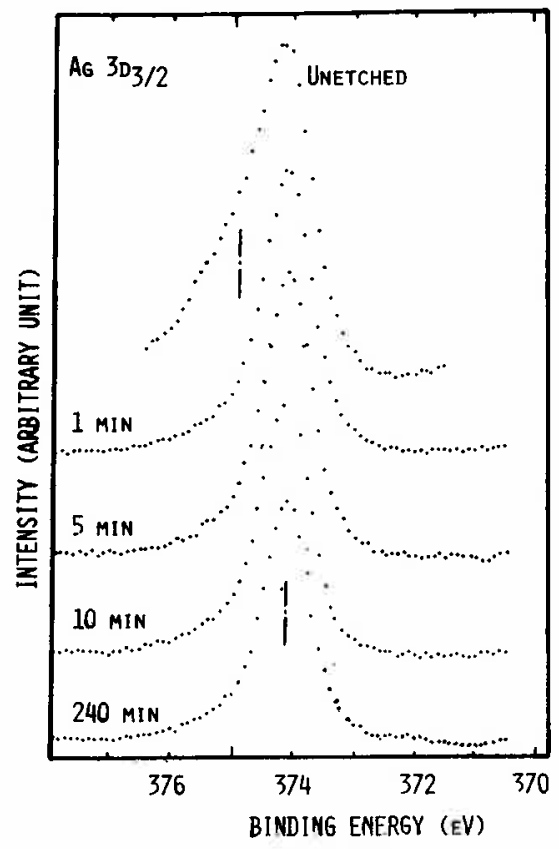

(a)

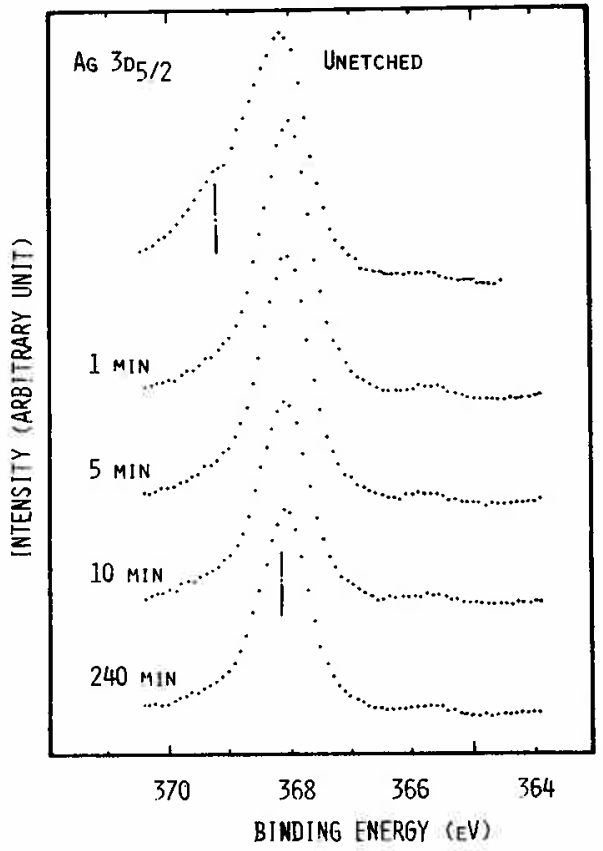

(b)

Figure 4. X-Ray photoelectron spectra of $\mathrm{Ag} 3 \mathrm{~d}_{3 / 2}, 3 \mathrm{~d}_{5 / 2}$ levels of $\mathrm{Ag}$ coated with PAA and etched by argon ion beam for 1, 5, 10, and $240 \mathrm{~min}$. 


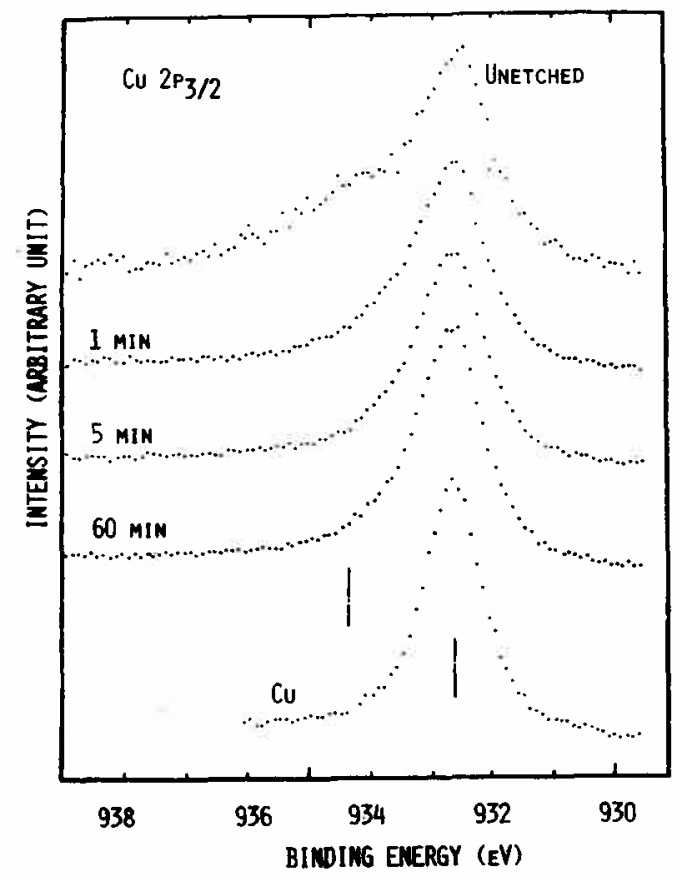

Figure 5. X-Ray photoelectron spectra of $\mathrm{Cu} 2 \mathrm{p}_{3 / 2}$ level of $\mathrm{Cu}$ coated with PAA and etched by argon ion beam for 1, 5, and $60 \mathrm{~min}$ and pure $\mathrm{Cu}$ metal.

$369.15 \mathrm{eV}$. This shoulder disappeared gradually because of the $\mathrm{Ar}^{+}$-ion etching. Profile of $\mathrm{Ag} \mathrm{3d_{3/2 }}$ level does not show good symmetry. S. Evans showed that no significant change occurred in the 3d signal throughout the oxidation other than some loss of intensity. ${ }^{17}$ So it seems that binding energy of this shoulder in the $3 \mathrm{~d}_{5 / 2}$ signal does not correspond to that of silver oxide, but a product of the chemical reaction between polyacrylic acid and the silver surface. Medium adhesive strength of silver ${ }^{16}$ to the cements is caused by the chemical reaction between PAA and the silver surface.

Experimental ESCA spectra of $\mathrm{Cu}$ coated with PAA are illustrated as function of $\mathrm{Ar}^{+}$-ion etching duration in Figure 5. The profile of $\mathrm{Cu} 2 \mathrm{p}_{3 / 2}$ level on the unetched sample shows a peak at $932.53 \mathrm{eV}$ and shoulder at $934.38 \mathrm{eV}$. This shoulder disappeared gradually by $\mathrm{Ar}^{+}$-ion etching. The binding energy at the peak corresponds to a pure $\mathrm{Cu}$ metal state. The binding energy of the shoulder is larger than that of $\mathrm{Cu}_{2} \mathrm{O}$ and $\mathrm{CuO}$ in the literature ${ }^{17,18}$ and does not coincide with the satellite peak of copper oxides. H. P. Gregor, L. B. Luttinger et al. showed the following reaction of $\mathrm{Cu}$ and PAA: $: 10$

$$
\mathrm{R}-\mathrm{COO}^{-}+\mathrm{Cu}^{2+} \rightarrow \mathrm{RCOOCu^{+ }}
$$

The shoulder of the spectrum seems to correspond to the product of this reaction. Ida et al. showed that the adhesive force of these cements to copper is strong. ${ }^{16}$ The chemical reaction corresponding to the shoulder in the spectrum seems to contribute to the strong adhesive force of these cements to $\mathrm{Cu}$. 


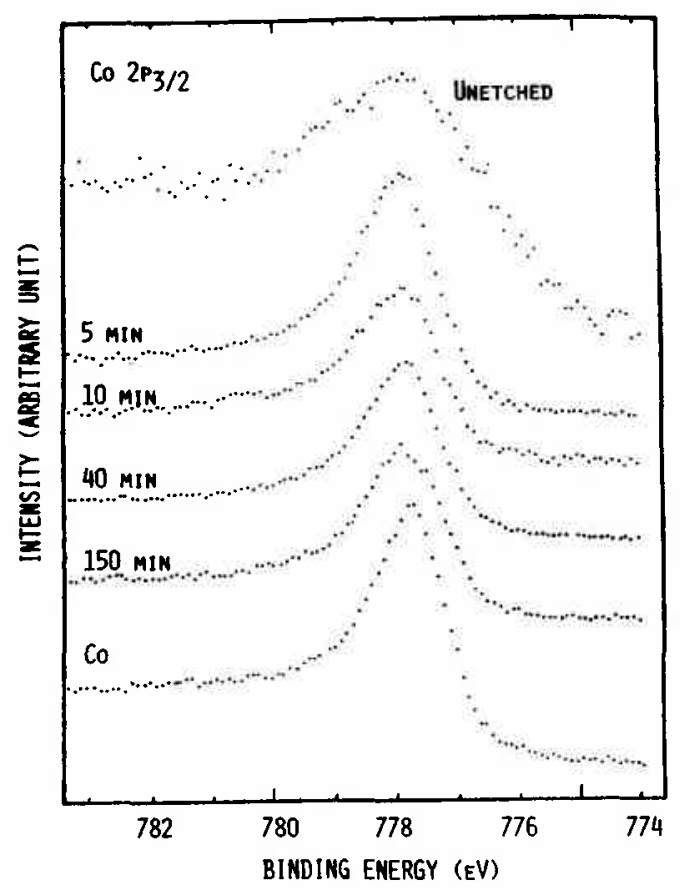

Figure 6. X-Ray photoelectron spectra of Co $2 p_{3 / 2}$ level of Co coated with PAA and etched by argon ion beam for 5, 10, 40, and $150 \mathrm{~min}$ and pure Co metal.

\section{Cobalt and chromium}

Experimental ESCA spectra of Co coated with PAA are illustrated as a function of $\mathrm{Ar}^{+}$-ion etching duration in Figure 6. Profile of $\mathrm{Co} 2 p_{3 / 2}$ level on the unetched sample shows a peak at $777.85 \mathrm{eV}$ and two shoulders at $779.55 \mathrm{eV}$ and $782.35 \mathrm{eV}$. These shoulders disappear by $\mathrm{Ar}^{+}$-ion etching for $5 \mathrm{~min}$. Binding energy of the peak corresponds to that of metallic state of Co. ${ }^{19}$ These shoulders correspond to cobalt oxides in the literature ${ }^{19}$ Previous work shows that the adhesive force of these cements to cobalt is slight. ${ }^{16}$ The reason is that the cobalt oxide film is very weak allowing the oxide film to peel off easily from the metal matrix. Adhesive forces of these cements to cobalt oxide seem to be strong, but the cobalt oxide film peels off easily producing weak adhesion to the metal.

Experimental ESCA spectra of $\mathrm{Cr}$ coated with PAA are illustrated as a function of $\mathrm{Ar}^{+}$-ion etching duration in Figure 7. Profile of $\mathrm{Cr} 2 \mathrm{p}_{1 / 2}$ level on an etched sample for $1 \mathrm{~min}$ show a peak at $583.61 \mathrm{eV}$ and two shoulders at $586.08 \mathrm{eV}$ and $588.25 \mathrm{eV}$. A profile of $\mathrm{Cr} 2 \mathrm{p}_{3 / 2}$ level show a peak at $574.23 \mathrm{eV}$, and two shoulders at $576.48 \mathrm{eV}$ and $578.25 \mathrm{eV}$. These peak and shoulders correspond to $\mathrm{Cr}, \mathrm{Cr}_{2} \mathrm{O}_{3}$, and $\mathrm{CrO}_{3}$, respectively in a previous work. ${ }^{20}$ The profile of a spectrum on a sputtered sample of $10 \mathrm{~min}$ shows an unsymmetric figure which has a swelling at the high binding energy side. A symmetric profile can not be obtained from a polished pure chromium surface which 


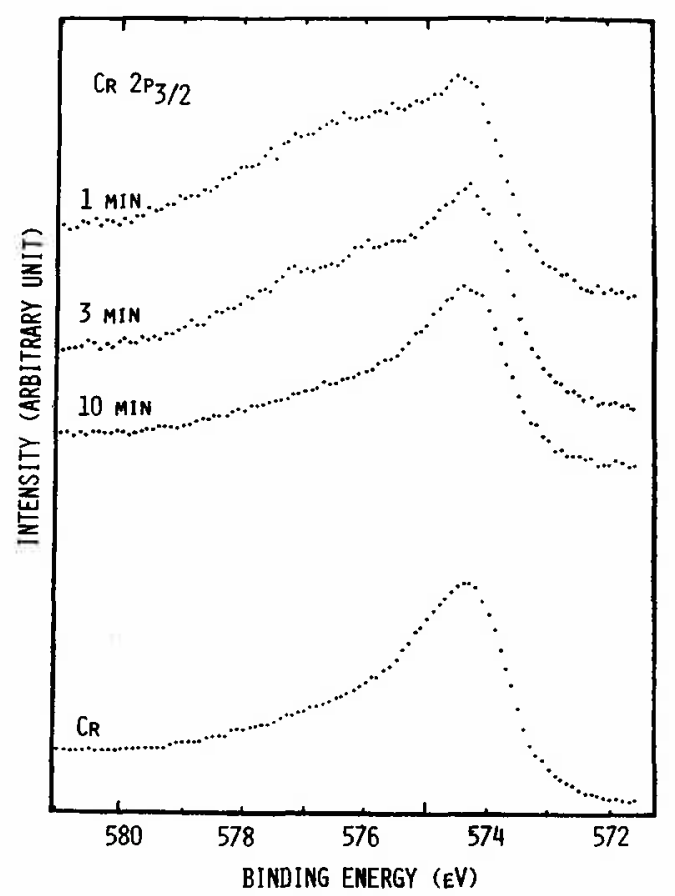

(a)

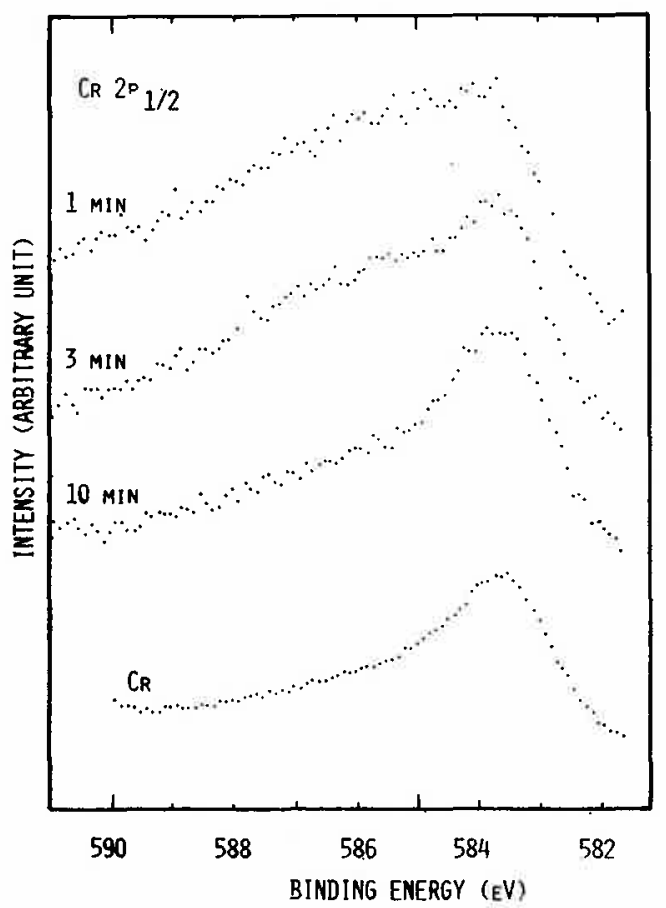

(b)

Figure 7. X-Ray photoelectron spectra of $\mathrm{Cr} 2 \mathrm{p}_{1 / 2}, 2 \mathrm{p}_{3 / 2}$ levels of $\mathrm{Cr}$ coated with PAA and etched by argon ion beam for 1, 3, and $10 \mathrm{~min}$ and pure $\mathrm{Cr}$ metal. 
also was sputtered by $\mathrm{Ar}^{+}$-ion beam for a very long time. This shows that a passive film of chromium oxide is formed on metal matrix firmly. S. M. Skinner and B. Yamaguchi et al showed that the adhesive force of dielectric adhesive materials to oxidized metals is strong, ${ }^{21,22}$ for the surface potential of metal oxide is higher than that of pure metal surface. This result corresponds to previous work that the adhesive force of these cements to chromium is strong. ${ }^{16}$ These results explain the strong adhesive force of the cements to stainless steel and to cobalt-chromium alloys. ${ }^{23}$

\section{Tin and indium}

Experimental ESCA spectra of Sn coated with PAA are illustrated as function of $\mathrm{Ar}^{+}$-ion etching duration in Figure 8. The profile of a $3 \mathrm{~d}_{3 / 2}$ level on unetched sample shows three peaks at $493.33 \mathrm{eV}, 495.47 \mathrm{eV}$, and $497.30 \mathrm{eV}$. Profile of $3 \mathrm{~d}_{5 / 2}$ level on unetched sample show three peaks too at $484.89 \mathrm{eV}$, $487.08 \mathrm{eV}$, and $488.78 \mathrm{eV}$. With increased etching time, the highest binding energy peak diminished first. The middle binding energy peak disappeared second, and the lowest binding energy peak persisted longest. This suggests that three different chemical states of the $\mathrm{Sn}$ atom are located at the interface between PAA and metal surface. ESCA spectra of standard Sn compounds are measured to assign these peaks. The lowest binding energy peak is assigned to the pure $\mathrm{Sn}$ metal state as shown in Figure 9. The middle binding energy peak corresponds to the $\mathrm{Sn}$ state in $\mathrm{SnO}_{2}$. The highest binding energy peak, marked by an arrow in Figure 8, is assigned to a signal originated from Sn atoms combined with carboxylate groups of PAA. The strong adhesive force of the cements to $\mathrm{Sn}$ metal is derived from the chemical reaction corresponding to the highest binding energy peak. The present experimental results explain McLean's observation that the cements have very small adhesive strength to $\mathrm{Au}$ and $\mathrm{Pt}$, but have strong adhesive forces to tinned $\mathrm{Au}$ and $\mathrm{Pt}^{24}$

Experimental ESCA spectra of In coated with PAA are illustrated as a function of $\mathrm{Ar}^{+}$-ion etching duration in Figure 10. A profile of In $3 \mathrm{~d}_{3 / 2}$ level on unetched sample shows three peaks at $451.15 \mathrm{eV}, 452.55 \mathrm{eV}$, and $454.40 \mathrm{eV}$. Profile of In $3 \mathrm{~d}_{5 / 2}$ level on unetched sample show three peaks at $443.70 \mathrm{eV}, 445.01 \mathrm{eV}$, and $446.76 \mathrm{eV}$. With increased etching time the highest binding energy peak diminish first. The middle binding energy peak disappeared second, and the lowest binding energy peak remained. This demonstrates that three different chemical states of In atoms are located at the interface between PAA and metal surface. ESCA spectra of standard In compounds were measured to assign these peaks. The lowest binding energy peak is assigned to the pure In metal state as shown in Figure 11. The middle binding energy peak corresponds to the In state in $\operatorname{In}_{2} \mathrm{O}_{3}$. The highest binding energy peak, marked by an arrow in Figure 10, is assigned to a signal originated from In atoms combined with carboxylate groups of PAA. The strong adhesive force of the cements to $\mathrm{Ag}$-In alloy ${ }^{23}$ is certainly contributed by the chemical reaction producing the highest binding energy peak. 


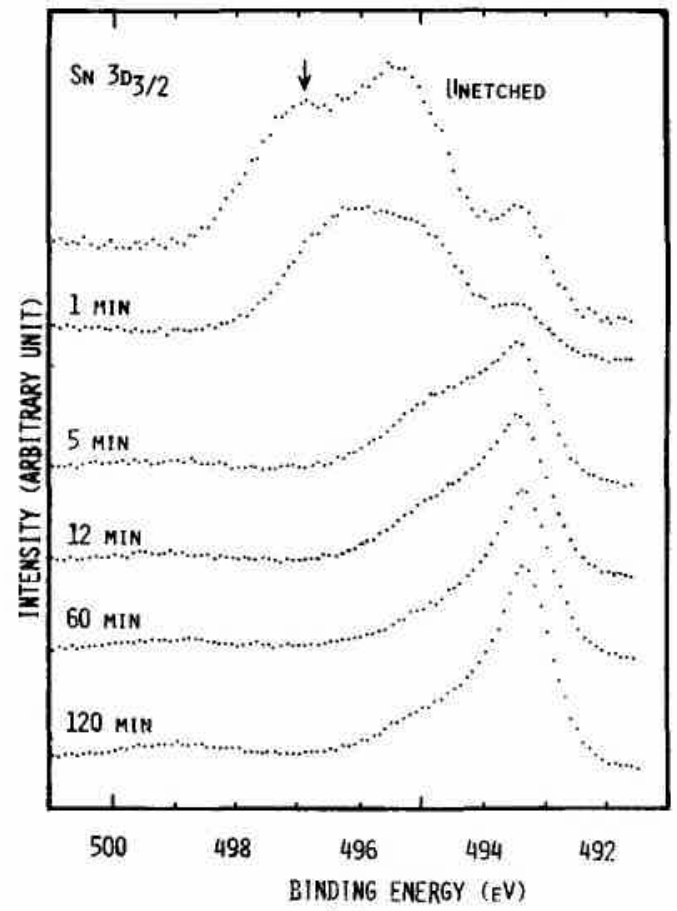

(a)

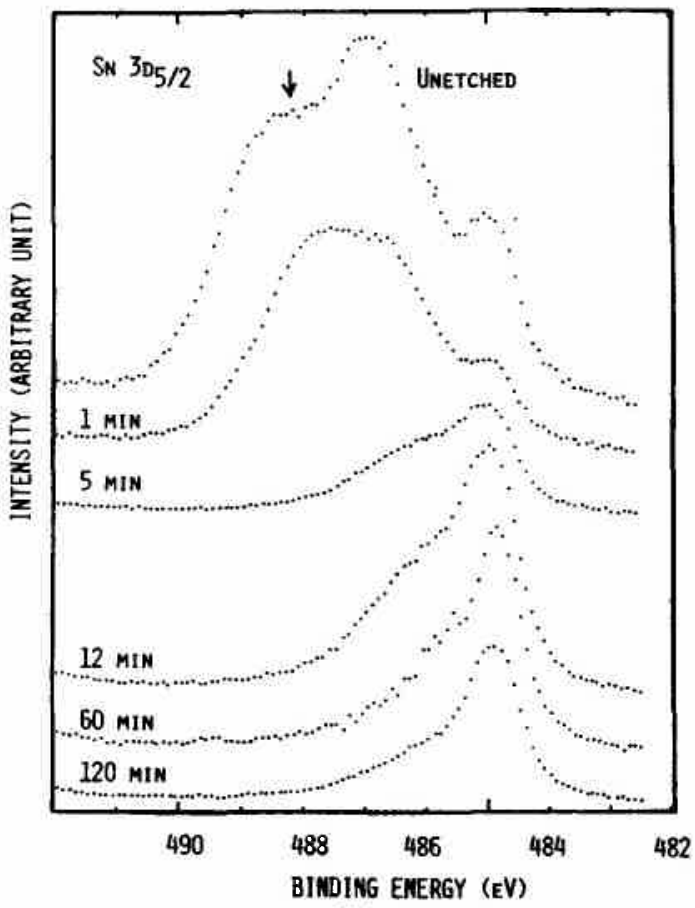

(b)

Figure 8. X-Ray photoelectron spectra of $\mathrm{Sn} 3 \mathrm{~d}_{3 / 2}, 3 \mathrm{~d}_{5 / 2}$ levels of $\mathrm{Sn}$ coated with PAA and etched by argon ion beam for 1, 5, 12, 60, and $120 \mathrm{~min}$. 


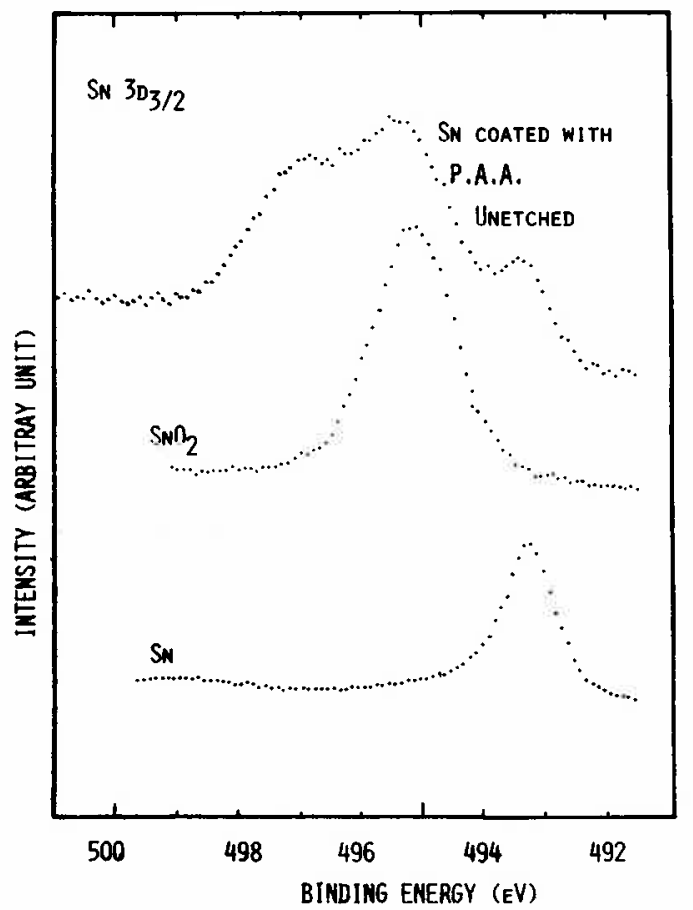

(a)

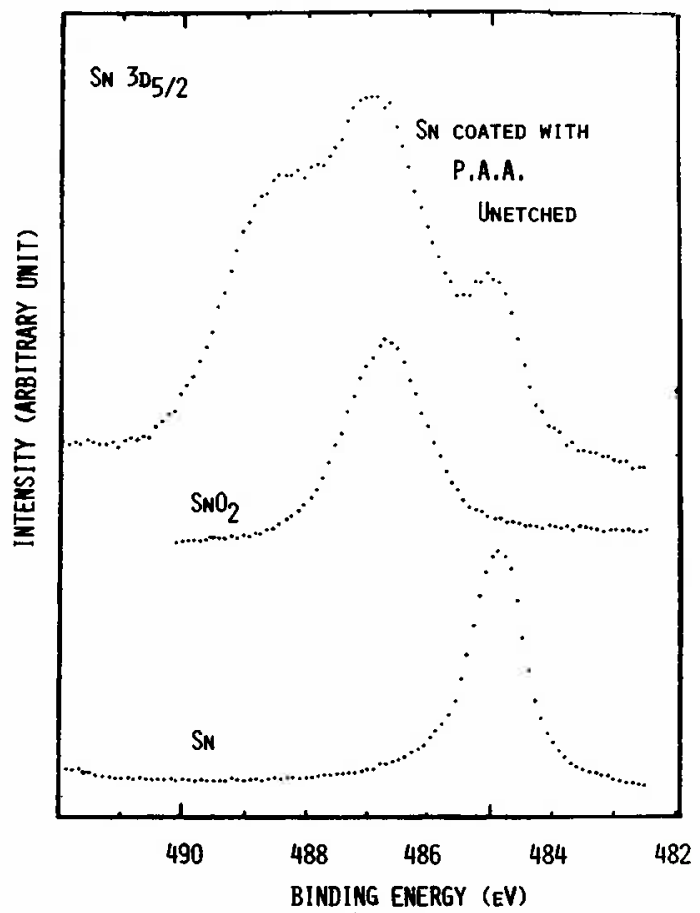

(b)

Figure 9. X-Ray photoelectron spectra of $S n 3 d_{3 / 2}, 3 d_{5 / 2}$ levels of $S n$ coated with $\mathrm{PAA}, \mathrm{SnO}_{2}$, and pure $\mathrm{Sn}$ metal. 


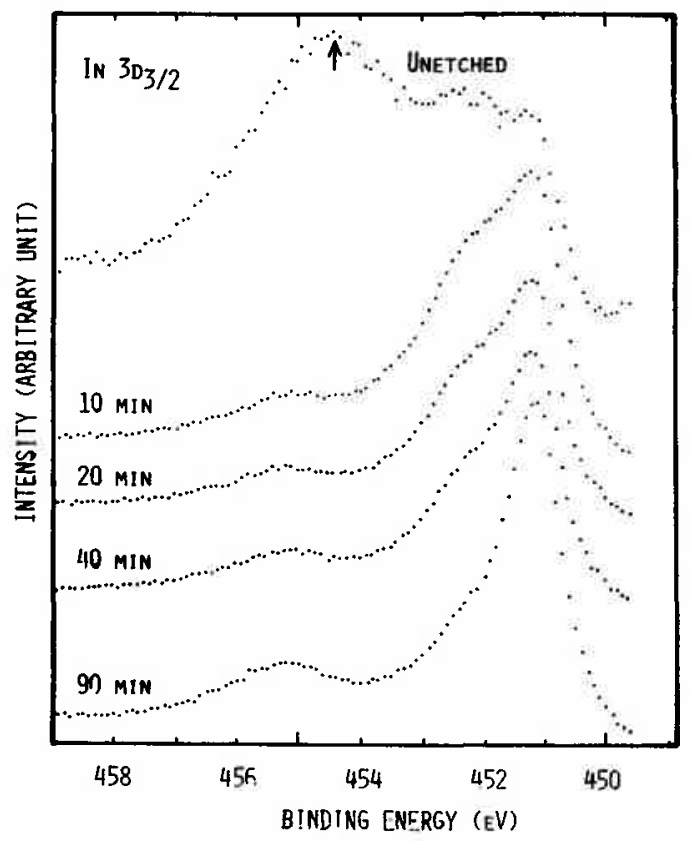

(a)

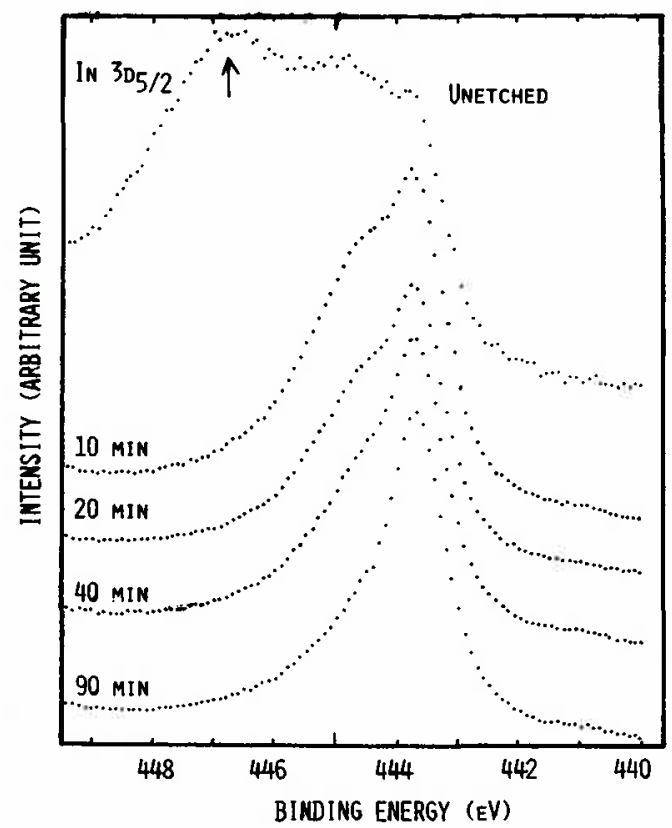

(b)

Figure 10. X-Ray photoelectron spectra of In $3 d_{3 / 2}, 3 d_{5 / 2}$ levels of In coated with PAA and etched by argon ion beam for 10, 20, 40, and $90 \mathrm{~min}$. 


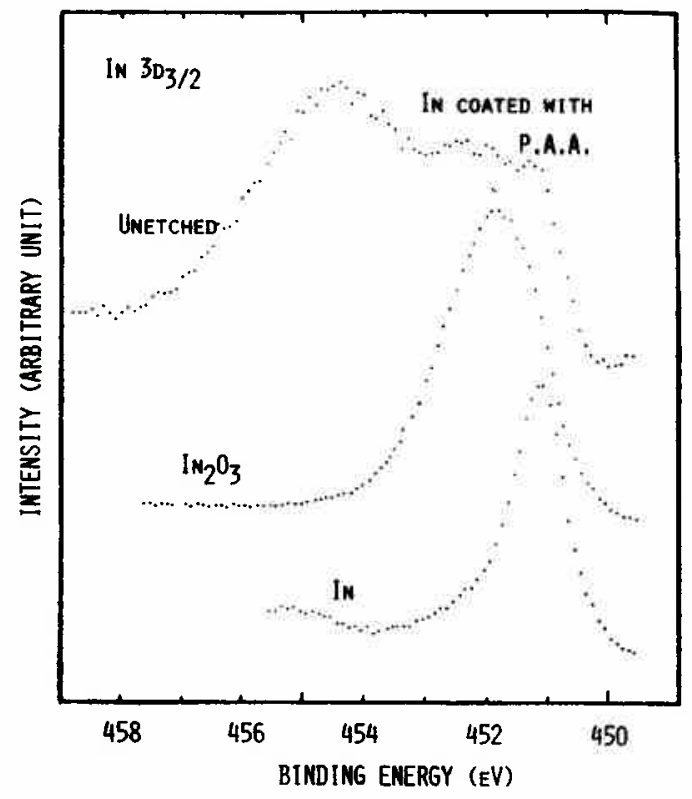

(a)

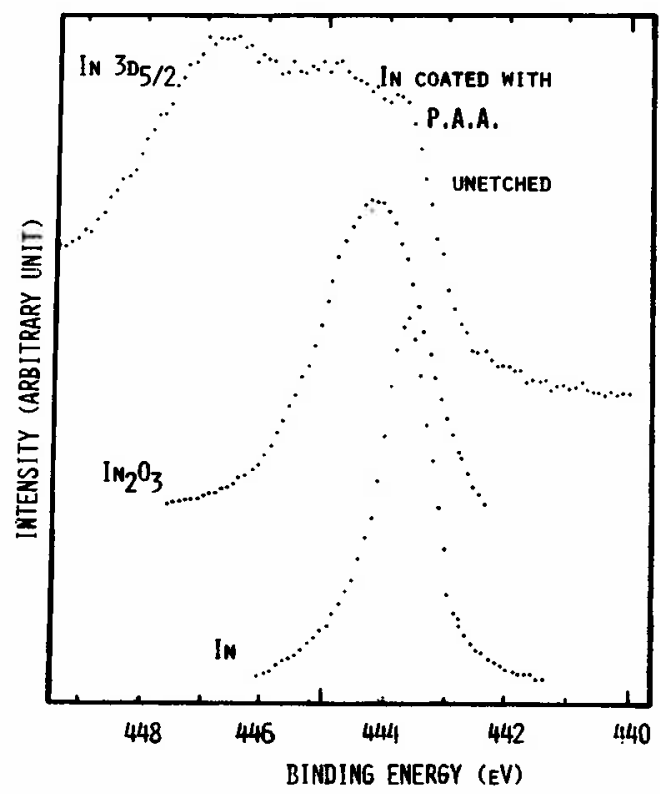

(b)

Figure 11. X-Ray photoelectron spectra of In $3 d_{3 / 2}, 3 d_{5 / 2}$ levels of In coated with $\mathrm{PAA}, \mathrm{In}_{2} \mathrm{O}_{3}$ and pure In metal. 


\section{Comparison of the experimental results with actual cementation}

The ESCA measurement in electron spectrometer requires very high level of vacuum, so the metal samples were dehydrated after painting of PAA. It is a different point compared with actual cementation process with water.

In an actual cementation during dental treatment an aqueous solution of PAA is mixed with the cement powder. During mixing, free carboxylate groups of PAA react with metal ions in the cement powder and form a salt. ${ }^{12}$ The amount of free carboxylate groups decreases rapidly with time after mixing. ${ }^{25}$ When metal and tooth substance contact the PAA after mixing of the cement, there is a diminished number of free carboxylate groups available to react with the metal and tooth substance. It is expected that the large majority of carboxylate groups of PAA react with metal ions in the cement powder, and the minor part of carboxylate groups of PAA react with the metal restoration and tooth substance. This might be able to explain why the adhesive force of the cement is not as that suggested by the chemical reaction with PAA and metal restorations demonstrated by the ESCA measurement of this study.

\section{CONCLUSION}

ESCA spectra of metal coated with PAA were measured as a function of $\mathrm{Ar}^{+}$-ion beam etching duration. The adhesion mechanism of the cements was examined by comparison of ESCA results and adhesive strength of the cements to various metals studied in previous work. The following conclusions were obtained:

1. Chemical reactions with chemical shifts in ESCA spectra did not occur when $\mathrm{Au}$ and Pt were coated with PAA. This could explain the weak adhesive strength of the cements to the noble metals, $\mathrm{Au}$ and $\mathrm{Pt}$.

2. When silver was coated with PAA, it reacted with the carboxylate groups of PAA. This chemical reaction contributed to the medium adhesive force of silver to PAA. The chemical reaction of copper and PAA resulted in a strong adhesive force.

3. When cobalt and chromium were coated with PAA, oxides were formed on the metal matrix. But the binding force of cobalt oxide and the cobalt matrix is very weak, allowing the oxide film to peel off easily, so the adhesive force of the cements to cobalt is very small. A passive film of $\mathrm{Cr}_{2} \mathrm{O}_{3}$ adheres on the chromium matrix firmly, so the adhesive force of these cements to chromium is very strong.

4. When tin and indium are coated with PAA, $\mathrm{SnO}_{2}$ and $\operatorname{In}_{2} \mathrm{O}_{3}$ are formed. Chemical product of Sn and In with PAA are formed over the oxide film, these reaction contributes to a strong adhesive force of the cements to $\mathrm{Sn}$ and In.

5. In an actual cementation, it is expected that the large majority of carboxylate groups of PAA react with metal ions in the cement powder, and the minor part of carboxylate groups of PAA react with the metal restoration. 
This might be able to explain why the adhesive force of the cement is not as that suggested by the chemical reaction with PAA and the metal restorations demonstrated by the ESCA measurement of this study.

The author wishes to thank Dr. F. Ito, Prof. K. Suzuki, Prof. K. Nagaoka, and Prof. W. A. Richter for XPS data and helpful discussions.

\section{References}

1. S. Crisp and A.D. Wilson, "Reaction in glass ionomer cements: I. Decomposition of the powder," J. Dent. Res., 53, 1408-1413 (1974).

2. S. Crisp, M. A. Pringer, D. Wardleworth, and A. D. Wilson, "Reaction in glass ionomer cements: II. An infrared spectroscopic study," J. Dent. Res., 53, 1414-1419 (1974).

3. S. Crisp and A. D. Wilson, "Reaction in glass ionomer cements: III. The precipitation reaction," J. Dent. Res., 53, 1420-1424 (1974).

4. D. C. Smith, "A new dental cement," Br. Dent. J., 125, 381-384 (1968).

5. D. C. Smith, "Medical and dental applications of cements," J. Biomed. Mater. Res. Symp., 1, 189-205 (1971).

6. D. R. Beech, "A spectroscopic study of the interaction between human tooth enamel and polyacrylic acid," Arch. Oral Biol., 17, 907-911 (1972).

7. H. P. Gregor, L. B. Luttinger, and E. M. Loebl, "Metal-polyacrylate complexes. I. The polyacrylic acid-copper complex," J. Phys. Chem., 59, 34-40 (1955).

8. H. P. Gregor, L. B. Luttinger, and E. M. Loebl, "Metal-polyelectrolyte complex. IX. Complex of polyacrylic acid with magnesium, calcium, manganese, cobalt, and zinc," J. Phys. Chem., 59, 990-991 (1955).

9. A. Ikegami, "Hydration and ion binding of polyelectrolytes," J. Poly. Sci. Assoc., 2, 907-921 (1964).

10. H. P. Gregor, L. B. Luttinger, and E. M. Loebl, "Metal-polyelectrolyte complex. I. The polyacrylic acid-copper complex," J. Phys. Chem.,59, 34-40 (1955).

11. A. L. Jacobson, "Configurational effects on binding of magnesium to polyacrylic acid," J. Poly. Sci., 57, 321-336 (1962).

12. S. Crisp, H.J. Prosser, and A.D. Wilson, "An infrared spectroscopic study of cement formation between metal oxides and aqueous solution of polyacrylic acid," J. Mater. Sci., 11, 36-48 (1976).

13. M. Klasson, J. Hedman, A. Berndtsson, R. Nilsson, and C. Nordling, "Escape depth of x-ray excited electrons," Physica Scripta , 5, 93-95 (1972).

14. K. Siegbahn, C. Nordling, A. Fahlman, R. Nordling, K. Hamrin, et al., Atomic, molecular and solid state structure studied by means of electron spectroscopy, Almovist \& Wiksells Boktryckeri Ab, Uppsala, (1967).

15. J.S. Solomon and D. Hanlin, Adhesive-adherend bond joint characterization by Auger electron spectroscopy and photoelectron spectroscopy, Poly. Sci. Technol., 12A, 103-122 (1980).

16. K. Ida, Y. Moriaki, and R. Yamaga, "Adhesion of polyacrylate cements to metals and alloys," J. Jap. Res. Soc. Dent. Mat. Appl., 30, 259-269 (1973).

17. S. Evans, E. L. Evans, D. E. Parry, M. J. Tricker, M. J. Walters, and J. M. Thomas, "Ultra-violet and $\mathrm{x}$-ray photoelectron spectroscopic studies of oxygen chemisorption on copper, silver, and gold," Faraday Discuss. Chem. Soc., 58, 97-105 (1974).

18. G. Schön, "ESCA studies of $\mathrm{Cu}, \mathrm{Cu}_{2} \mathrm{O}$, and $\mathrm{CuO}$," Surface Sci., 35, 96-108 (1973).

19. Y. Okamoto, H. Nakano, T. Imanaka, and S. Teranishi, "X-ray photoelectron spectroscopic studies of catalysts-supported cobalt catalysts-," Bull. Chem. Soc. Jap., 48, 1163-1168 (1975). 
20. K. Asami and K. Hashimoto, "The $x$-ray photoelectron spectra of several oxides of iron and chromium," Corrosion Sci., 17, 559-570 (1977).

21. S. M. Skinner, R. L. Savage, and J. E. Rutzler, "Electrical phenomena in adhesion. I. Electron atmospheres in dielectrics," J. Appl. Phys., 24, 438-450 (1953).

22. B. Yamaguchi and $H$. Hattori, "Relation between surface potential of metals and adhesive property of organic coatings," J. Metal Finishing Soc. Jap., 9, 17-22 (1958).

23. H. Noguchi, "Evaluation of adhesive cement to the tooth," J. Tohoku Dental Univ., 8, 43-57 (1981).

24. J.W. McLean, "A new method of bonding dental cements and porcelain to metal surface," Operative Dent., 2, 130-142 (1977).

25. T. Nasu, K. Nagaoka, I. Ohtsuka, and H. Aoki, "Chemical reaction at the interface between tooth enamel and adhesive materials containing polyacrylic acid," Bull. Yamagata Univ. (Eng.), 18, 25-29 (1984).

Received July 8, 1985

Accepted August 12, 1985 